\title{
O FUTURO DA INDÚSTRIA FARMACÊUTICA GLOBAL AS PERSPECTIVAS JAPONESA, AMERICANA E EUROPÉIA
}

$\star$ Gilson Nunes de Paula

7951401@lepi.fgvsp.br

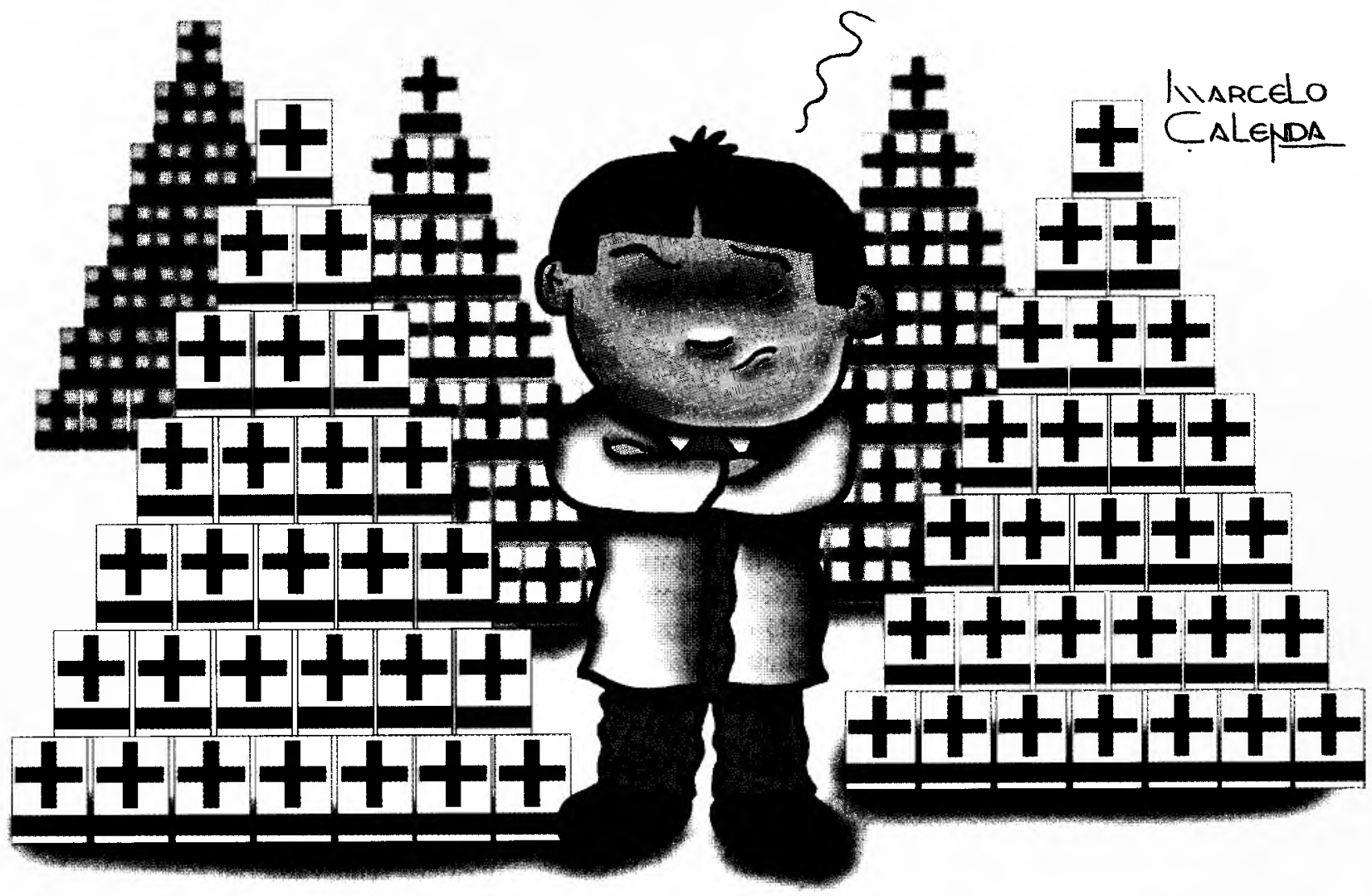

\section{PALAVRA-CHAVE:}

tecnologia, inovação, pesquisa e desenvolvimento, atratividade de mercado, globalização, competência estratégica, estratégia competitiva, estrutura de mercado, fusóes, aquisições, empresa japonesa, indústria farmacêutica.

\section{KEY WORDS:}

technology, innovation, research and development, market attractiveness, globalization, strategic competence, market structure, mergers, acquisitions, Japanese company, pharmaceutical industry.

\section{$\star$ Mestre em Economia pela EAESP/FCV e Gerente de Consultoria pela Trevisan Corporate Finance.}

(rae@eaesp.fgvsp.br) Assinatura Email 


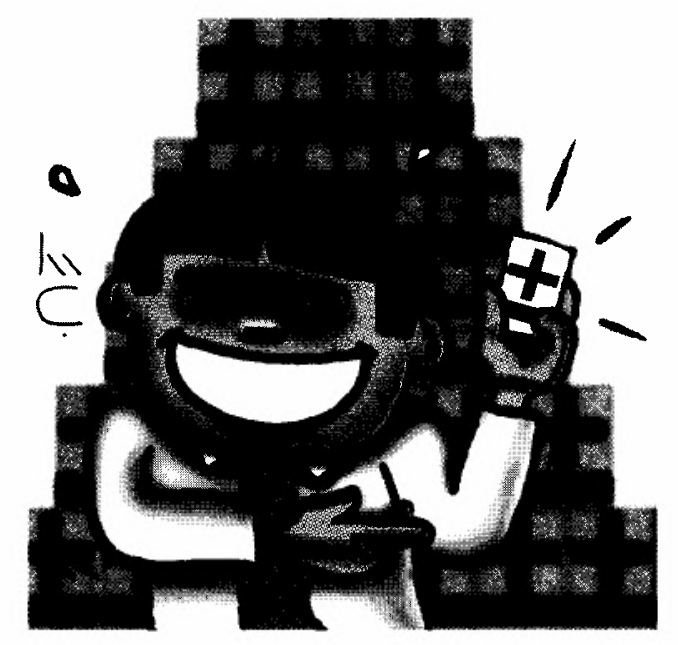

Por que não existe nenhuma empresa japonesa entre as líderes mundiais na indústria farmacêutica em termos de atratividade de mercado e competências organizacionais $e$ culturais?

Why there are no Japanese leaders to date
on global pharmaceutical industry,
considering the market attractiveness and
organizational/cultural competencies?

D esde $o$ aparecimento, após a Segunda Guerra Mundial, de sistemas de saúde custeados com recursos públicos, nos países desenvolvidos, a indústria farmacêutica tem experimentado rápido crescimento e rentabilidade altamente atraente. As margens de lucro das empresas bem-sucedidas têm-se situado uniformemente no nível de $30 \%$ ou mais. Em razão dessa uniformidade, o tamanho de uma companhia farmacêutica, em termos absolutos, é um bom indicador de seu desempenho global. Referências sobre esse desempenho podem ser encontradas na "Tabela da Liga", em nível mundial. E quando se examina o desempenho das essas empresas na Tabela da Liga, verificase um dado surpreendente: é a ausência de empresas japonesas entre a 15 maiores do mundo.

As empresas japonesas têm dominado a indústria eletrônica e a automobilística nos últimos 10-15 anos, mas o mesmo não acontece com a área de produtos farmacêuticos. Será que não há nada inerentemente superior na administração japonesa ou será apenas uma questão de tempo para que as empresas japonesas venham a dominar este campo de batalha crucial no futuro?

Para se responder a essa pergunta, é preciso primeiro tentar entender o passado. $\mathrm{O}$ que foi preciso, até hoje, para uma empresa farmacêutica tornar-se líder mundial na sua área, e por quê as empresas japonesas, no geral, estiveram ausentes desse sucesso no passado? Depois, é crucial entender as recentes tendências e descontinuidades nos anos 90 , tanto no âmbito do mercado como um todo como no das empresas em particular.

Respondidas estas perguntas, pode-se, finalmente, partir para o entendimento da questão fundamental: quem se encontra na melhor posição para o sucesso global no mercado farmacêutico depois da década de 90 ?

\section{PERSPECTIVA HISTÓRICA: POR QUE NENHUM LÍDER JAPONÊS ATÉ HOJE?}

Os produtos farmacêuticos, que compreendem produtos medicinais e drogas receitáveis e não-receitáveis, respondem por $33 \%$ da produção de produtos químicos dos países da OECD (organizaçāo para Cooperação e Desenvolvimento Econômico). Na maioria dos países dessa organização, o setor farmacêutico tende a se concentrar mais do que a indústria de produtos químicos em geral, embora ainda permaneça relativamente fragmentado. Dentre as vendas das cinco maiores empresas mundiais - em termos de percentual das vendas totais das indústrias - somente $11 \%$ referem-se às da área de produtos farmacêuticos, contra $37 \%$ do campo das telecomunicações, $50 \%$ da indústria automobilística e $95 \%$ da aeroespacial. As dez maiores empresas farmacêuticas do mundo respondem por apenas $20 \%$, aproximadamente, das vendas da indústria. Os níveis de concentração mundial aumentaram nos mercados de produtos individuais, com as fusões e aquisições entre as princi- 
pais empresas fabricantes de drogas, tendência essa que tem se acentuado recentemente.

As empresas farmacêuticas fabricantes de produtos éticos na América e na Europa compreendem um grupo relativamente pequeno de grandes multinacionais fortemente envolvidas em P\&D (Pesquisa e Desenvolvimento) e alguns milhares de empresas menores empenhadas em pesquisa especializada ou em produtos genéricos, em sua maioria, e naqueles destinados a venda em balcăo de farmácia (OTC, Over the Counter). Nos principais países da Europa, as grandes multinacionais controlam mais de $60 \%$ do mercado interno de produtos farmacêuticos. A Glaxo e a ICI, no Reino Unido, a Hoechst e a Bayer, na Alemanha, a Rhone-Poulenc Rorer, na França e a Ciba- Geigy e Sandoz and Hoffmann-La Roche, na Suíça, respondem pela maior parte das vendas de drogas em seus mercados internos e também exportam muito. As principais empresas farmacêuticas dos EUA sāo a Merck (o maior produtor mundial, em termos de receita), a SmithKline Beecham (que se fundiu com a Beecham, do Reino Unido), a American Home Products, a Eli Lilly e a Abbott Laboratories. Todas as 15 empresas farmacêuticas mais importantes do mundo (ver quadro 1) têm marcado forte presença nos EUA, o maior mercado mundial em termos de valor, mas - o que é mais significativo - com relação desproporcional, em termos de lucros.

Embora o mercado de produtos farmacêuticos no Japão seja o segundo maior no mundo, as firmas japonesas desse ramo são, tradicionalmente, menores do que as dos EUA e da Europa. Esta indústria, altamente fragmentada, compóe-se de 1.500 empresas, das quais o grupo japonês Takeda ocupa um modesto $16^{\circ}$ lugar, mesmo tendo $98,6 \%$ de seu resultado proporcionado pelo mercado japonês. Vários fatores de mercado têm contribuído para essa posição.

Ao se medir o tamanho/rentabilidade das companhias ocidentais, verifica-se que estas têm dominado uniformemente o mercado global de produtos farmacêuticos, tal como demonstrado gráfico 1, o que pode ser atribuído, em grande parte, aos aspectos explicitados a seguir. De maneira estilizada, parece razoável supor que os

\section{QUADRO 1}

1990

1. Merck

2. Bristol'Squibb

3. Glaxo

4. Smith Kline Beecham

5. Ciba-Geigy

6. AMHO/Robins

7. Hoechst

8. Johnson \& Johnson

9. Bayer

10. Sandoz

11. Lilly

12. Pfizer

13. Roche

14. Rhône-Poulenc Rorer

15. Merell Dow Marion
Fonte: PAULA, Gilson N. The global pharmaceutical industry in the 1990 s. London: EIU, 1991 ค. 36.

sucessos anteriores da indústria farmacêutica decorreram, primeiramente, da atratividade do mercado e, segundo, das "competências organizacionais/ culturais distintivas":

- atratividade do mercado;

- âmbito do mercado;

- apoio governamental;

- método de comercialização;

- organizacional/cultural;

- enfoque em P\&D;

- gerenciamento (de processos e alianças);

- conhecimentos especializados em assun-

tos legais/normativos;

- vendas e marketing.

\section{ATRATIVIDADE DO MERCADO DA INDÚSTRIA FARMACÊUTICA}

\section{Âmbito do mercado}

A maioria das companhias químicas japonesas fazem parte de uma rede mais ampla de empresas (keiretsu), mas assumiu papel menos importante ao atuar como "fornecedoras" de matéria-prima para as indústrias de exportação do Japão (carros e produtos eletrônicos). Isso fez com que milhares de companhias químicas se concentrassem em umas poucas linhas de produtos na área para atender a esses importantes consumidores, com preços mais favoráveis, bem ao contrário da maneira como se desenvolveram gigantescas com- 


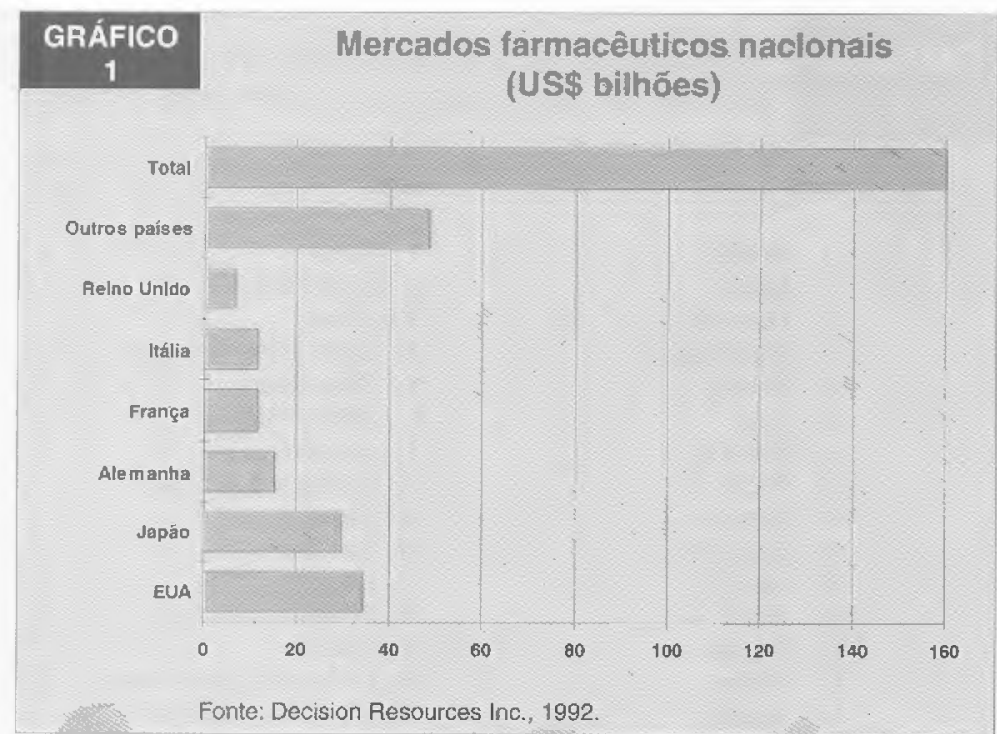

panhias ocidentais, verticalmente integradas (tais como a BASF, a ICI, a Du Pont e a Rhône-Poulenc) com forte presença no mercado de produtos farmacêuticos. A estrutura do keiretsu significa também que, com a estrutura de capital que lhe é peculiar, é muito mais difícil ocorrerem aquisições, o que faz com que empresas japonesas apoiem-se mais no crescimento natural do que no crescimento por meio de aquisiçôes. Comparadas às fusões e às aquisições em larga escala ocorridas nos EUA e Europa, as do Japão, incluindo as joint ventures, são de porte relativamente modesto.

No setor de produtos farmacêuticos, as carteiras de produtos japoneses têm mostrado tendenciosidade "pró-Ásia" (ou seja, inclinam-se para os produtos anti-infecciosos e de nutrição, cuja fabricação tem diminuído no resto do mundo), ao invés de irem no sentido de uma carteira global (ou seja, com mais ênfase em produtos cardiovasculares e de combate à dor). Com relação às drogas japonesas bem-sucedidas em escala global, as companhias têm mostrado a tendência de licenciá-las para comercializaçăo por empresas que atuam em mercados estrangeiros, ao invés de usá-las como "trampolim" para a expansão internacional. As companhias químicas japonesas têm-se preocupado mais em proteger seu mercado interno contra a entrada de multinacionais estrangeiras do que em expandir-se para além das fronteiras japonesas. Esses fatores mostram que, embora grandemente auto-induzido, o âmbito de crescimento dos produtos farmacêuticos japoneses tem sido limitado, em comparaçâo com o de suas similares ocidentais.

\section{Apoio governamental}

Existe espaço para controvérsia, mas muitos acreditam que o MTTI (Ministery of Industry Tecnology) desempenhou um papel crucial no desenvolvimento das indústrias automobilística e de produtos eletrônicos no Japão. A proteçāo, desde os primórdios, combinada a uma forte atuaçăo na coordenação da pesquisa e desenvolvimento aplicados, pode ter facilitado muito o estabelecimento da supremacia japonesa nessas áreas. Até o início da década de 80, o MITI năo havia identificado a biotecnologia como "a tecnologia para o futuro", não tendo partido disso, portanto, como um caminho potencial para o processo farmacêutico.

Em geral, o Japão tem sido criticado por seu baixo nível de pesquisa básica, fato que, sem dúvida, contribuiu para a inferioridade dos seus produtos farmacêuticos. É, portanto, pouco provável que essa crítica venha de companhias farmacêuticas ocidentais. Embora o Japão se orgulhe de gastar em P\&D 2,9\% de seu PIB (Produto Interno Bruto), a mais alta taxa de todas, a composição desses gastos difere substancialmente das do Ocidente. Apenas $1 \%$ da P\&D do Japão vai para pesquisa básica, cerca de $10 \%$ são para a pesquisa aplicada e $89 \%$ destinam-se ao desenvolvimento de produtos $-o$ que tem beneficiado as indústrias de carros e de eletrônicos, mas pode ter prejudicado o desenvolvimento dos produtos farmacêuticos. Além disso, a P\&D custeada com recursos públicos representa aproximadamente apenas $25 \%$ do total (os restantes 75\% vêm de empresas), quando na Alemanha essa taxa é de 33\% e, nos EUA, Reino Unido e França, $50 \%$ ou mais (embora os números relativos aos países ocidentais se apresentem distorcidos pelos gastos com defesa nacional). Assim, anteriormente, as companhias farmacêuticas do Ocidente beneficiaram-se dos subsídios governamentais à pesquisa básica muito mais do que as japonesas. Na verdade, o MITI reconhece que, nos anos 80 , a busca de superioridade em biotecnologia, por parte do Japão, foi gravemente pre- 
judicada pelo início tardio de investigações nesse campo, pela falta de pesquisadores em pesquisa básica e por ter uma infra-estrutura tecnológica subdesenvolvida, se comparada à dos países ocidentais. Além do mais, dois motivos importantes fizeram com que o Japão, nos últimos dez anos, tivesse pouco êxito na superação desse atraso: a maior liberalização do comércio por meio do GATT (General Agreement of Tariffs and Trade) e um crescente sentimento "anti-japonês" no comércio, em decorrência dos êxitos alcançados pelo Japáo nas indústrias de carros e de produtos eletrônicos mostram que o escopo da proteçáo à "indústria incipiente", por parte do MITI, tem sido limitada; a biotecnologia está progredindo depressa demais, abrangendo uma área também muito ampla, e com menos metas futuras "óbvias" a serem coordenadas por um poder central. Esta falta de clareza é ilustrada pelo fato de existirem muitas entidades governamentais lutando pela participação no desenvolvimento da biotecnologia.

Uma força final do mercado -, esta, influenciada pela legislação -, que prejudicou muitas firmas japonesas foi a taxa de aumento de preços de produtos farmacêuticos nos anos 80 . O Japão tomou a dianteira de muitos países ocidentais na escalada de custos nesse setor, principalmente porque encontrava-se em situaçāo muito pior. O governo japonês queria reduzir os gastos nacionais com remédios, que consumiam 30\% de seus US $\$ 180$ billhões destinados à saúde, muito maior do que os $5 \%$ de outros países desenvolvidos.

No Japão, os gastos com remédios por ano, por pessoa, são os mais elevados, ou seja, US\$228. A Alemanha, que vem em seguida, gasta US\$ 169 por pessoa. Os remédios custam caro no Japão, principalmente por causa da forma de sua comercialização e venda. Os médicos japoneses nâo só receitam os remédios como os fornecem. Eles os compram, primeiro, dos atacadistas, com um desconto sobre os preços oficiais (yakka) estabelecidos pelo governo, e, pelos mesmos remédios que receitam a preços oficiais, são reembolsados pelo mesmo governo. Esse sistema estimula os médicos a "receitarem demais" ou a receitarem remédios caros. O clínico geral japonês médio ganha US\$327 mil por ano; o americano, US\$ 213 mil em média. As constantes reduçōes de custos decretadas, no Japão, pelo Ministério de Saúde e Bem-Estar, ao longo de toda a década de 80 , prejudicaram muito a sua indústria farmacêutica. Enquanto os preços das drogas nos EUA aumentaram $40 \%$ entre $1982 \mathrm{e}$ 1988 , no Japão sofreram diminuição de 39\%. Só em 1991, a Shionogi e a Fujisawa tiveram, nos preços, reduçốes médias de preço de $9,5 \%$ e $9 \%$, respectivamente.

Devido ao início tardio e ao aumento das pressōes internas, os produtos farmacêuticos japoneses apresentaram tendência a se internalizar, ao invés de expandir-se para o exterior. As indústrias ocidentais, ao contrário, aos poucos foram sendo capazes de entrar no mercado japonês muitas vezes, como o último passo rumo à globalização. As companhias farmacêuticas agora respondem por $25 \%$ das vendas de remédios no Japão; os remédios ocidentais, por sua vez, representam $40 \%$ das vendas no país. Nota curiosa é que os dois principais produtos ali comercializados foram inventados por indústrias ocidentais.

\section{Método de comercialização}

Finalmente, como citado antes, as companhias farmacêuticas no Japão enfrentam um ambiente de marketiny e comercialização único e complexo. Aproximadamente $90 \%$ dos remédios são diretamente receitados por médicos, e não vendidos diretamente por farmácias, como no Ocidente. O que é mais importante, apenas $10 \%$ dos 19 mil médicos do país receitam exclusivamente, deduzindo-se daí que $17 \mathrm{mil} \mathrm{de-}$ les precisam ter estoque regular de remédios. As empresas, então, precisam proceder a esse fornecimento, fornecer por intermédio dos 400 atacadistas do país ou de seus próprios representantes (conhecidos como detailmen). Dessa prática resultaram significativos overheads de vendas. Além disso, tradicionalmente as empresas vêm dando aos clínicos gerais descontos de até $30 \%$ sobre os preços oficiais dos remédios (yakka), o que, por sua vez, faz com que muito do "aluguel" vá para os clínicos gerais - e não para as companhias farmacêuticas -, e os benefícios fiquem com estas últimas, principalmente devido aos volumes "inflacionados" resultantes desse sistema. Os esforços recentes do governo para 
reduzir preços e "ocidentalizar" a comercialização têm prejudicado as empresas japonesas, no sentido de torná-las capacitadas para expandir-se no mercado internacional.

\section{Competências distintivas de organizacionais/culturais}

Tomando por base os antecedentes da indústria, são identíficados e discutidos nesta seção quatro fatores de sucesso.

\section{Enfoque em P\&D}

No caso de muitos produtos químicos que são commodities ou mercadorias a granel, a concorrência baseia-se, em grande parte, no preço. Em contraposição, quando se tratam de produtos químicos e farmacêuticos especializados, a concorrência baseia-se principalmente na inovaçāo e diferenciação do produto, mais do que no preço. Portanto, para a maioria das firmas agro-químicas e farmacêuticas, a percentagem de custos associados à $P \& D$ e marketing é relativamente alta, sendo bem pequena a proporção realmente associada aos custos de fabricaçāo (ver gráfico 2).

Os gastos com $P \& D$ nos EUA, no setor de produtos químicos e farmacêuticos, subiu de aproximadamente US $\$ 8$ bilhóes em 1985 para mais de US\$ 10 bilhões em 1988, dos quais, cerca de metade gasto no setor de produtos farmacêuticos. As empresas americanas e européias há muito superaram suas colegas japonesas nos gastos com

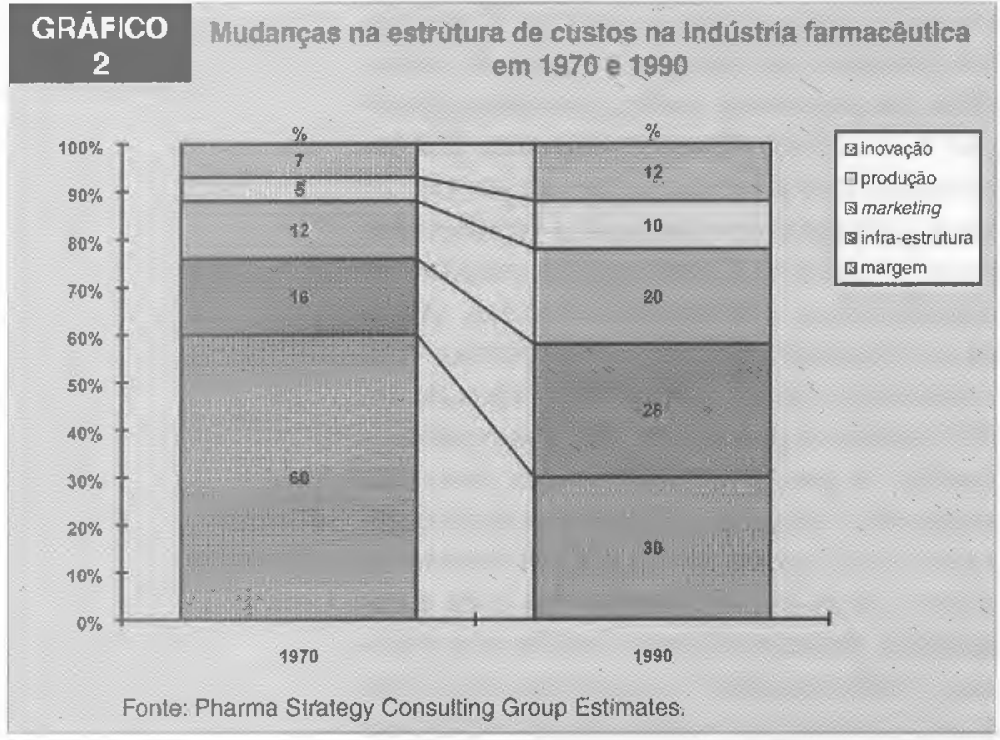

P\&D de produtos químicos (tanto em termos absolutos como em percentuais), um procedimento só recentemente foi intensificado no Japão. No passado, o apoio à tecnologia importada sob licença fez com quese enfatizasse o desenvolvimento, em detrimento da pesquisa básica; a falha proteção às patentes fez com que as firmas japonesas se concentrassem na pesquisa de processos ao invés de fazê-lo na de produtos. Um terço dos remédios vendidos no Japão vem de fora (sob licença). No Japão, os fabricantes dedicaram-se a desenvolver antibióticos - cuja venda, no mundo todo, tem diminuído -, e só a partír dos anos 80 as suas companhias farmacêuticas começaram a cuidar desse atraso em P\&D. Duas forças incentivaram esse crescimento $\mathrm{da}$ P\&D farmacêutica no Japão:

- os lucros das empresas que não tinham novos produtos foram diminuídos em razão das reduçōes de preços feitas pelo governo, como já citado. Assim, os únicos remédios a terem preços especiais são aqueles incorporados de novos conceitos, de maior eficácia e em condiçōes de contribuir de forma notável para o tratamento;

- o custo de desenvolvimento de um novo composto subiu drasticamente: colocá-lo no mercado passou de aproximadamente US\$ 50 milhóes, ao final dos anos 60, para mais de US $\$ 250$ milhóes, em meados da década de 80 (incluindo-se aí o custo de compostos que nāo chegavam ao mercado).

$\mathrm{O}$ índice de gastos japoneses com P\&D em relação às vendas subiu de $7,25 \%$, em 1982, para 11,1\%, em 1992: uma melhoria substancial, mas ainda assim abaixo da média ocidental, em torno de $15 \%$.

\section{Gerenciamento (de processos e alianças)}

O IED (Investimento Estrangeiro Direto) desempenhou papel importante nas estratégias globais das principais companhias farmacêuticas ocidentais. O IED em produtos farmacêuticos é o maior de todos os segmentos da indústria química, devido à diferenciação de mercados e à variação de regulamentos e normas para esse tipo de produto, de um país para outro. Estima-se que o IED responda pelo dobro do valor dos produtos farmacêuticos que 
entram no mercado internacional. A maioria das companhias farmacêuticas ocidentais nesse campo mantêm a produção de instalaçóes de montagem onde quer que haja mercados. As operaçôes das multinacionais ajudaram a superar obstáculos às exportaçóes e a recuperar os altos custos de P\&D.

O IED no setor de produtos farmacêuticos da Europa é relativamente alto. Os produtos farmacêuticos fabricados pelos próprios países a seguir citados representam, com relaçăo ao valor da produção: aproximadamente $90 \%$ na Bélgica, $60 \%$ na Espanha, 50\% na França, Itália e Áustria, e $35 \%$ no Reino Unido, Alemanha e Holanda. Nesses países as companhias farmacêuticas respondem por $20 \%$ ou menos da produção; e os países escandinavos são os que têm menos companhias nesta área. Grande parte do investimento estrangeiro na Europa é feito por firmas americanas e suíças: quase $20 \%$ - ou USS 9 bilhões - das vendas mundiais das companhias farmacêuticas americanas foram feitos por subsidiárias que produzem no exterior. As firmas suiças dominam seu pequeno mercado interno, enquanto as estrangeiras agora respondem por cerca de $18 \%$ da produçăo de produtos farmacêuticos nos EUA.

As firmas estrangeiras respondem por aproximadamente $15 \%$ da produção japonesa de produtos farmacêuticos. Essa proporção está crescendo rapidamente, com o aumento dos investimentos das empresas de países da OECD no Japāo. Em 1988, as companhias farmacêuticas japonesas tinham 15 instalações de produção nos EUA, 14 em Formosa e 11 na Europa, e no Japão havia 97 empresas farmacêuticas de propriedade de estrangeiros.

Também a indústria farmacêutica no Canadá e Austrália está, em grande parte, em mãos de estrangeiros, que respondem por $65 \%$ ou mais do valor da produção total.

A P\&D de produtos farmacêuticos está também se internacionalizando: das 30 maiores companhias de remédios, 23 têm instalaçōes de P\&D nos EUA, 16 no Reino Unido, 11 na França, 7 na Alemanha e 7 na Itália.

Comparativamente, as companhias farmacêuticas japonesas têm sido lentas na abordagem da globalizaçâo, concentrando-

\begin{tabular}{|c|c|c|c|}
\hline $\begin{array}{cl}\text { QUADRO } & \text { Prin } \\
2 & \text { dep }\end{array}$ & $\begin{array}{l}\text { dipais con } \\
\text { opriedade }\end{array}$ & $\begin{array}{l}\text { hpanhias farm } \\
\text { de estrangei }\end{array}$ & $\begin{array}{l}\text { cêticas } \\
\text { os (1991) }\end{array}$ \\
\hline Empresar & $\begin{array}{l}\text { Renda } \\
\text { declarada } \\
1989 / 90 \\
\text { (US\$ milhōes) }\end{array}$ & $\begin{array}{l}\text { Propriedade de } \\
\text { estrangeiros }\end{array}$ & $\begin{array}{c}\% \\
\text { participação }\end{array}$ \\
\hline Bayer Yakuhin. & 145,2 & Bayer & 75,6 \\
\hline Banyu Pharmaceutical & 122,6 & Merck Sharp \& Dohme & 50,8 \\
\hline Nippon Glaxo & 47,7 & Glaxo & 50,0 \\
\hline Nihon Shering & 39,3 & Schering $A G$ & 100,0 \\
\hline Nippon Weflçome & 37,4 & Wellcome & 55,0 \\
\hline Nippon Boehringer Ing. & 33,4 & Boehringer Ing. & 100,0 \\
\hline Japan Upjohn & 22,1 & Upjohn & 55,0 \\
\hline ICl Pharma. & 19,9 & $\mathrm{ICl}$ & 60,0 \\
\hline Warner-Lambert. & 17,2 & Warner-Lambert & 100,0 \\
\hline Fujisawa Fisons & 15,7 & Fisons & 65,0 \\
\hline
\end{tabular}

se mais na defesa do seu mercado interno. Na verdade, em 1988 a Yamanouchi Pharmaceutical foi uma das primeiras da área a levar a sério os mercados internacionais, quando instalou fábricas de remédios na Irlanda.

Outro instrumento de expansāo usado por firmas ocidentais tem sido as fusōes e aquisiçōes e joint venture transnacionais. O quadru 2 ilustra alé que ponto as firmas ocidentais têm sido bem-sucedidas, mesmo na difícil tarefa de entrar no mercado japonês. Em contraposiçāo, no decorrer dos anos 80, as empresas farmacêuticas japonesas raramente se empenharam nessa modalidade de crescimento tático na arena internacional: a Mitsubishi Kasei (a maior companhia química do Japão, em 1991) tinha apenas $15 \%$ de sua receita gerada fora do Japão, comparada à das empresas ocidentais ilustradas no quadro 3 .

\section{Conhecimentos especializados sobre assuntos legais/normativos}

As patentes são vitais para indústrias baseadas em P\&D, tais como as de produtos químicos. Estas indústrias dependem da proteção às patentes e, em menor grau, da proteção às marcas registradas, tanto nos mercados nacionais como estrangeiros, para terem um retorno adequado sobre os gastos com $P \& D$. Conseguir a especialização necessária para apoiar o registro de patentes e sua proteção fora do país é uma 


\begin{tabular}{|c|c|c|c|c|c|c|}
\hline $\begin{array}{c}\text { QUADRO } \\
3\end{array}$ & \multicolumn{6}{|c|}{$\begin{array}{l}\text { Análise geográfica das vendas das principais } \\
\text { companhias farmacêuticas europélas } 1991 \text { (\%) }\end{array}$} \\
\hline & Locais & uropa & $\begin{array}{c}\text { América } \\
\text { do } \\
\text { Norte }\end{array}$ & $\begin{array}{l}\text { América } \\
\text { Latina }\end{array}$ & Ásia & Outros \\
\hline BASF (Alemanha) & 34.2 & 31.1 & 20.1 & 4.4 & 6.1 & 4.1 \\
\hline Hoechst (Alemanha) & 61.9 & & 19.1 & 4.9 & 14.1 & \\
\hline Bayer (Alemanha) & 67.4 & & 19.3 & 4.5 & 7.2 & 1.6 \\
\hline ICl (Reino Unido) & 23.2 & 26.0 & 28.3 & & 17,4 & 5.1 \\
\hline Rhône-Poulenc (França) & 23.0 & 25.0 & 21.2 & 6.3 & 7.0 & 17.5 \\
\hline Ciba-Geigy (Suiça) & 45.0 & & 31.0 & 7.0 & 12,0 & 5.0 \\
\hline Akzo (Holanda) & 8.9 & 54.1 & 21.5 & 15.6 & & \\
\hline Solvay (Bélgica) & 10.1 & 66.9 & 12.8 & 3.8 & 2.9 & 3.5 \\
\hline DSM (Holanda) & 17.8 & 61.9 & 11.5 & 8.8 & & \\
\hline
\end{tabular}

tarefa de competência bem definida. Em suas iniciativas de globalização, importantes firmas ocidentais desenvolveram essa especialização ao longo dos anos 80 , atuando de modo a minimizar o impacto de fatores subsequientes que fizeram cair o retorno sobre patentes químicas, isto é, o atraso no Registro e nos Testes, os produtos genéricos e a violação das patentes.

Uma das causas de diminuição do retorno sobre patentes tem sido a crescente dificuldade de se cumprirem as exigências governamentais atinentes a produtos quimicos. Outro motivo é o tempo demasiadamente longo na fase de testes e registros, fato que diminui relativamente o prazo de proteção à patente.

Nos anos 80 , os procedimentos tornaram-se dispendiosos e onerosos, em razão do interesse do público por questões de saúde e segurança, associado ao lançamento de novos produtos químicos e drogas. Vai levar muito tempo para que um pedido ou uma emissão de patente para desenvolvimento de mercado e regularização seja aprovado antes de o produto ser comercializado. Em muitos países, o prazo de patente começava a correr enquanto era obtida a aprovação, resultando daí um encurtamento do período durante o qual o produto poderia ser comercializado sob proteção à patente. A Comunidade Européia estima que, nos diferentes países da Europa, os atrasos no registro reduzem, dos 20 anos originais para cerca de nove, a vida útil da patente dos produtos farmacêuticos. Estudos feitos nos EUA mostram que a vida rentável de um novo remédio caiu para menos de oito anos.
Outra causa de "erosāo" no retorno sobre patentes farmacêuticas foi o crescimento dos produtos genéricos no decorrer da década de 80 . Esses produtos - cópias menos dispendiosas de drogas com marcas registradas mas com patentes vencidas respondem atualmente por quase um terço do mercado de drogas receitáveis nos EUA e Europa. Entidades governamentais do setor de saúde e empresas de seguros, principais compradores de produtos farmacêuticos em muitos países da OECD, encorajaram médicos a receitar mais remédios genéricos, em uma tentativa de reduzir os custos de tratamentos médicos. Muitos produtos com marca registrada, que, após o vencimento das respectivas patentes, poderiam, por muitos anos, continuar vendendo a uma taxa de $80 \%$, agora enfrentam concorrência acirrada dos remédios genéricos, reduzindo a receita $\mathrm{e}_{f}$ conseqüentemente, o potencial de P\&D das companhias farmacêuticas éticas.

Finalmente, a "erosão" nos retornos sobre patentes nos anos 80 foi causada pela violaçāo destes por empresas que imitam ilegalmente e comercializam produtos químicos patenteados. Tem crescido no mundo todo o uso desautorizado de patentes, em parte devido ao crescimento do comércio e dos investimentos estrangeiros na área de produtos químicos e ao desenvolvimento de tecnologia para imitação de produtos químicos. Como não têm gastos com $P \& D$, as firmas que fazem pirataria vendem os produtos por preços mais baixos, reduzindo o volume de vendas dos detentores das patentes e seu retorno sobre o investimento. Embora hajam tais problemas também nos países da $\mathrm{OECD}$, o uso desautorizado de patentes químicas ocorre com mais freqüência nos países que não fazem parte da organizaçāo, devido à natureza dos seus sistemas de proteção às patentes. Em muitos casos, os sistemas de patente em países nāo-membros têm como meta acelerar a transferência e a difusāo de tecnologia, além de promover o acesso à tecnologia estrangeira, para bem do desenvolvimento econômico. Estima-se que, na OECD, a indústria química -, fabricante de produtos farmacêuticos, produtos químicos de proteção industrial e fertilizantes, primordialmente-, sofre prejuízos econômicos anuais de US\$ 7 a 8 bilhōes, devido à violação de patentes. 


\section{TRANSIÇÃO ATUAL E RUPTURAS POTENCIAIS}

Atualmente não há dados que indiquem se a indústria farmacêutica continua em crescimento, mas há preocupação com as tendências de longo prazo, no sentido de estas vierem a resultar em deterioração contínua das bases dessa indústria. As preocupaçōes dos investidores estão voltadas para a disseminação dos esforços para restringir gastos com saúde nos EUA e no resto do mundo desenvolvido. Temese, nos EUA, a crescente importância dos programas de saúde gerenciados pelo governo e pelo setor privado, cujo efeito é tornar o preço dos remédios um fator de decisão de compra mais importante do que era antes. Embora a contenção de custos e a determinação de preços sejam, nitidamente, fatores negativos, há também algumas tendências positivas. $\mathrm{O}$ potencial de descoberta por meio da pesquisa, usando novos métodos como a biotecnologia, nunca foi tão grande; embora muitos produtos antigos sofram as pressões dos preços, a área de novos produtos está tendo mais proteção às patentes e preços decentes no mundo todo. Isso constitui mais um fator de pressão para que os orçamentos de $P \& D$ dêem resultados. Tais orçamentos situamse atualmente em torno de $15 \%$ do valor das vendas das principais companhias farmacêuticas do mundo ocidental (ver quadro 4).

Acima de tudo, a indústria farmacêutica mundial está passando por uma consolidaçāo global, na qual a fatia de mercado das maiores e melhores empresas deve crescer significativamente nos próximos 20 anos.

\section{Fatores de sucesso organizacionais/ culturais}

\section{Enfoque em P\&D}

Uma crescente pressão normativa, combinada a novas tecnologias dispendiosas tais como a biotecnologia e a terapia genética, sem dúvida fez crescer os custos de desenvolvimento de drogas. Por isto, há a necessidade de internacionalizaçāo da pesquisa e, em particular, do desenvolvimento, para que se lance um composto o mais rapidamente possível. Para enfrentar a queda dos preços e o aumento dos custos, a indústria terá de gerenciar mais eficien- temente a P\&D. Uma revolução gerencial está ocorrendo no âmbito da P\&D da indústria farmacêutica, com questôes como estas, que dizem respeito inclusive a seus diretores:

- onde encontrar compostos inovadores? A Pfizer calcula que $90 \%$ dos compostos em desenvolvimento vêm de pesquisas internas. Várias empresas têm se mostrado ansiosas para ter acesso a moléculas descobertas fora de suas organizaçōes, particularmente na indústria de biotecnologia, em rápido crescimento. A Roche participa como majoritária em grandes grupos biotecnológicos, enquanto outras, como a Merck e a Glaxo, preferem fazer acordos com empresas da área, em projetos individuais;

\begin{tabular}{|c|c|c|c|}
\hline $\begin{array}{c}\text { QUADRO } \\
4\end{array}$ & \multicolumn{3}{|c|}{ Despesas com P\&D de empresas ocidentais } \\
\hline Empresa & $\begin{array}{l}\text { Gastos com P\&D } \\
\text { (US } \$ \text { milhōes) }\end{array}$ & $\begin{array}{l}\text { Vendas } \\
\text { (US\$ milhões) }\end{array}$ & P\&D com \% de vendas \\
\hline Glaxo & 1052.7 & 7247.0 & 14.5 \\
\hline Merck & 987.8 & 8019.5 & 12.3 \\
\hline Roche & 953.3 & 4119.9 & 23.1 \\
\hline BMS & 845.0 & 5908.0 & 14.3 \\
\hline Hoechst & 785.8 & 6263.9 & 12.5 \\
\hline Bayer & 688.8 & 5306.4 & 13.0 \\
\hline Ciba-Geigy & 677.8 & 4052.3 & 16.7 \\
\hline Sandooz & 675.0 & 4440.7 & 15.2 \\
\hline SKB & 654.6 & 4370.1 & 15.0 \\
\hline J\&J & 569.0 & 3795.0 & 15.0 \\
\hline
\end{tabular}

- como escolher as áreas terapêuticas e os compostos a serem desenvolvidos? As moléculas nas quais deverăo investir: é uma questāo de desafio para os diretores de $P \& D$;

- como acelerar o tempo de colocação de uma droga no mercado? Para um composto arrasador, cada dia de demora pode custar à empresa até US\$ 1 milhão, e os diretores de P\&D têm que usar todas as artimanhas de que dispõem para acelerar o processo de desenvolvimento, enquanto asseguram o composto nos EUA, Japāo e Europa, garantindo ao grupo o mais rápido retorno possível sobre o investimento;

- como incorporar às experiências clínicas dados de estudos sobre economia de saúde? Estas, depois de demonstrar que as 
drogas são seguras e eficazes, têm que mostrar agora que elas são eficazes em termos de custos, reduzindo o tempo do doente no hospital ou fora do trabalho;

- como usar eficientemente a nova tecnologia de computadores (ou seja, economizando espaço e tempo)?;

- como gerenciar cientistas no mundo todo? Os grupos mais importantes têm P\&D nos EUA, Europa e Japão, o que traz muitas dificuldades logísticas.

Ao mesmo tempo que exigem resultados essenciais da P\&D farmacêutica, governos e clientes mostram-se menos dispostos a pagar pelas melhorias marginais das drogas já existentes. Das 53 novas apli-

\section{Embora o mercado de produtos}

$$
\text { farmacêuticos no Japão seja o }
$$

segundo maior no mundo, as firmas japonesas desse ramo são, tradicionalmente, menores do que as dos EUA e da Europa.

cações químicas (NCE) introduzidas no mundo todo em 1988, apenas quatro trouxeram o benefício terapêutico de tratar doenças intratáveis anteriormente - e um número um pouco maior oferece modestos progresso terapêutico. A indústria é obrigada a reconhecer que acabou-se o tempo em que podia lançar um produto com benefícios terapêuticos marginais apenas e torná-lo um sucesso principalmente mediante vendas bem planejadas e executadas e esforço de marketing. Para ser bemsucedido no novo ambiente, um produto precisa apresentar vantagens nítidas em relação às terapias já existentes (conforme promoções da Glaxo na década de 90).

Acima de tudo, é cada vez mais difícil dar uma definição precisa do mercado farmacêutico global, à medida que seus limites se confundem com os dos segmentos de produtos como os de diagnósticos e agroquímicos. Ao contrário, a "cola" empresarial que une atividades como, por exemplo, as drogas beta-bloqueadoras cardíacas da Zeneca e os produtos de proteí- nas micobacterianas para vegetarianas, parece ser de competência das ciências biológicas pesquisadas pelos especialistas da P\&D. Para funçóes de desenvolvimento e clínicas, esta competência essencial tende a ser da área terapêutica: a posição sem concorrentes da Glaxo e da SKB, nos tratamentos de úlcera, deve-se à invençāo e desenvolvimento, por ambas, dos chamados antagonistas de $\mathrm{H} 2$ e ao seu grande conhecimento sobre estes. Entretanto, mesmo sendo o conhecimento sobre pesquisa básica um setor específico, as técnicas de desenvolvimento podem ser habilidades passíveis de transferência: as invençōes de Tagamet e Propanolol, por James Black, foram para áreas terapêuticas inteiramente diferentes. Mesmo o que inicialmente parece conhecimento de determinado setor, pode mostrar-se capaz de impacto sobre muitos outros setores.

Novas entidades químicas desenvolvidas para uma área terapêutica podem acabar sendo comercializadas para um tratamento completamente diferente, por causa de vias comuns dentro do organismo. Por exemplo, as antigas fórmulas anti-histamínicas usadas para curar a alergia da febre do feno estão sendo agora amplamente substituídas por preparaçōes "mais limpas", mas o que foi antes considerado efeito colateral do tratamento da alergia foi relançado como remédio para dormir. Conseqüentemente, as companhias farmacêuticas deverão ser vistas cada vez mais como um conjunto de setores de competências de $\mathrm{P} \& \mathrm{D}$, e não como meras carteiras de produtos.

O Japăo parece ter assumido um compromisso com o desenvolvimento de especialistas embiotecnologia, mas, como se comentou anteriormente, é difícil visualizar uma evoluçāo semelhante àquela de seus sucessos coordenados pelo MITI, nas áreas de bens de consumo eletrônicos e carros. É improvável que as drogas produzidas com base na engenharia genética progridam além de certos nichos, pelo menos por dez anos, embora a biotecnologia, como técnica capacitadora, já seja a pedra de toque da P\&D farmacêutica. Se a biotecnologia continuar sendo principalmente um meio de desenvolvimento de produtos, ao invés de um fim em si mesma, a melhor estratégia do Japāo talvez seja desenvolver uma posição sólida de "espaço 


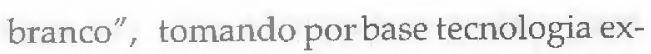
clusiva - tal como a dos anticorpos monoclonais - , mas entre segmentos terapêuticos tradicionalmente definidos. Isso poderia trazer também, a médio prazo, algumas recompensas, necessárias para o incentivo ao compromisso com a área de pesquisa pura: os sucessos tecnológicos japoneses tendem a ocorrer em áreas de pesquisa aplicada, e a mentalidade exigida para o gerenciamento de pesquisa básica de prazo mais longo talvez não se coadune com o modo de pensar japonês tradicional.

Gerenciamento (de processos e alianças)

Acredita-se, em geral, que o gerenciamento da tecnologia seja o fator mais importante para melhorar a inovação; o gerenciamento da cadeia de valor está sendo reconhecido como o método predominante de controle de custos e apropriação de recursos. À medida que aumentam os custos da inovação para o mesmo volume de produção, e à medida que os clientes se tornam mais sofisticados, o papel da administração tem que assumir um novo significado. Hoje e no futuro, a administraçāo terá de desempenhar um papel crucial no controle e monitoramento da velocidade e dircçāo das inovaçōes, pois somente os eficientes e economicamente eficazes sobreviverão. "Os custos e a inovaçāo substituem a inovaçäo somente como força motriz da vantagem competitiva na indústria farmacêutica nos anos $90^{\prime \prime}$.

Diminuir o tempo de colocação de uma nova droga no mercado será crucial para a competitividade das companhias farmacêuticas no futuro. Como tempo definitivamente é dinheiro, um número cada vez maior de empresas está tentando colocar seus produtos no mercado mais depressa do que nunca, para, assim, garantir a oportunidade de recuperar os custos da inovação e de assegurar o retorno sobre o investimento, antes que os produtos genéricos entrem em cena.

Hoje em dia - principalmente por causa da escalada dos custos de $P \& D$, das incertezas quanto às aplicaçōes de biotecnologia e da necessidade de recuperar receitas num prazo mais curto, para fugir à concorrência dos produtos genéricos -, firma nenhuma pode ter sucesso sem formar alianças e acordos cooperativos e/ou adquirir outras empresas. Os exemplos abaixo caracterizam algumas parcerias recentes:

- alianças de marketing entre firmas japonesas e companhias farmacêuticas ocidentais (por exemplo, a Takeda com a Abbot nos EUA, a Eisai com a Sandoze a Dai Nippon com a Rhone-Poulenc na Europa), para ganhar experiência de mercado;

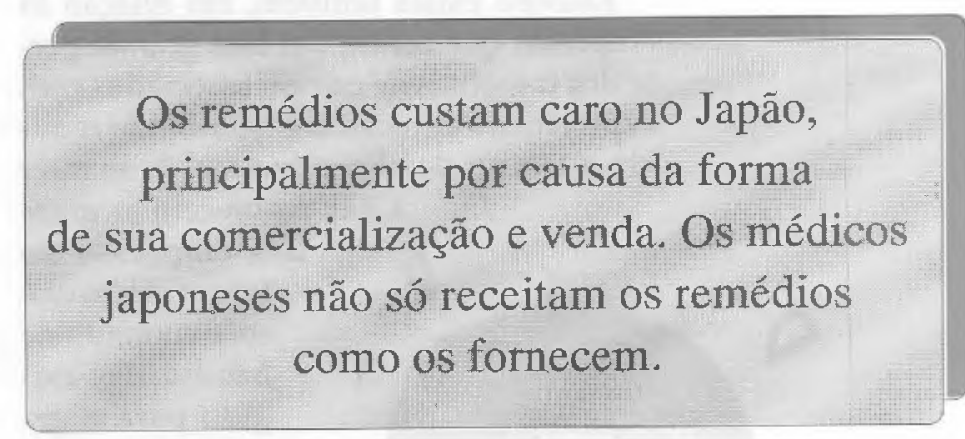

- aquisiçōes, pelos fabricantes, de produtos químicos (Du Pont \& Monsanto), empresas de bens de consumo $(P \& G$, Nestle e Kodak) e firmas japonesas (a Fujisawa comprou a LyphoMed nos EUA e a Klinge na Alemanha Ocidental, e a Sankyo comprou a Luitpold na Alemanha Ocidental) em expansão nos EUA e Europa estão acrescentando uma nova dimensāo. Com raízes em áreas de negócios completamente diferentes, elas possuem a capacidade de trazer estratégias não ortodoxas ao mercado.

\section{Conhecimento especializado sobre assuntos legais/normativos}

A indústria farmacêutica continua sendo o mercado mundial mais regulamentado, com exigências únicas para quem dele participa. "O tempo para comercializar" novas drogas depende das experiências clínicas, bem como de P\&D. A capacidade de assegurar aprovação rápida pelas autoridades (e, assim, minimizar a demora em obter o retorno) terá cada vez mais importância como vantagem competitiva, com o passar do tempo. As formulaçóes de drogas estão sendo padronizadas no mundo todo, e, por isto, está se tornando um elemento chave na vantagem competitiva a capacidade de coordenar experiências clí-
1. Ver Global pharmaceutical industry in the 1990s: the challenge of change. London: EUA, 1990. 
nicas simultâneas, para garantir a aprovações em diversos países. Além do mais, a manutençāo de Boas Práticas de Fabricação (GMP - Good Manufacture Practices), compatíveis com exigências de entidades normativas tais como a FDA (Food Drugs Administration) é crucial. Os recentes efeitos, de problemas de relacionamento entre a FDA e a Fisons é um exemplo de como as pequenas companhias farmacêuticas podem se empenhar para manter GMP, com resultados desastrosos.

Embora exista também, em relação às empresas que contratam fora grande parte dos trabalhos de campo associados com experiências clínicas, a exigência de reduzir o tempo de experiência e de manter GMP favorecerá as gran-

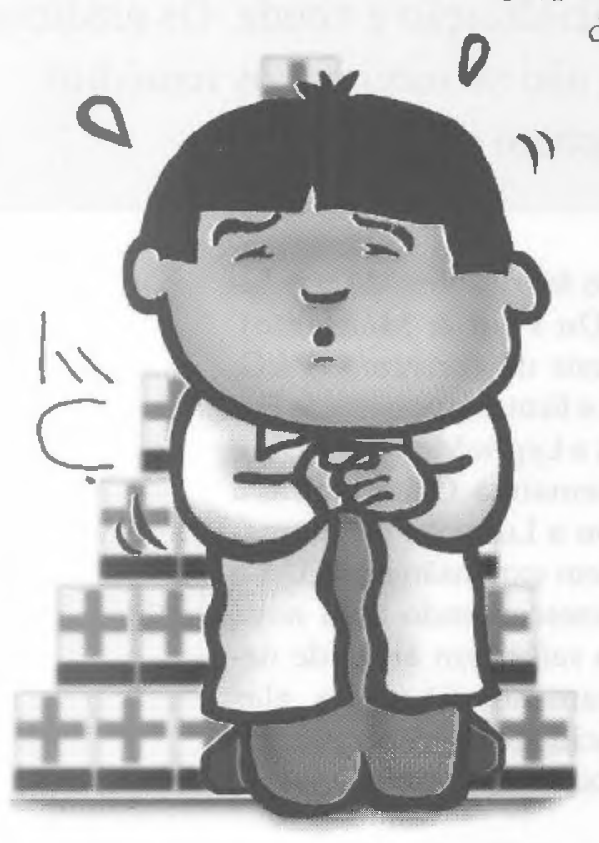

Vendas e marketing

A produção de drogas genéricas está crescendo no mercado principalmente devido ao apoio das entidades normativas e das companhias de seguro. Em 1989, na Alemanha Ocidental e nos EUA, os principais fabricantes em termos de vendas unitárias eram os de produtos genéricos. A tecnologia e a pesquisa mudaram o foco das doenças invasivas para os distúrbios degenerativos.

Nāo ficou claro ainda se a tendência para concentraçăo do poder de compra observada nos EUA se repetirá em outros locais. Sem dúvida, os NHS (National Health Sys- tem) estăo se esforçando cada vez mais para alavancar o poder de compra monopolístico de seus fornecedores $\mathrm{e}$, a continuar essa tendência, a necessidade de forças de venda em larga escala para visitar milhares de médicos pode não constituir mais uma barreira importante à sua entrada.

Não está claro, tampouco, se a habilidade dos japoneses na comercialização dos bens de consumo duráveis, tais como carros e equipamentos audiovisuais, será um bom indicador para o marketing farmacêutico. A necessidade de colocar um produto tecnicamente diferenciado é certamente comum a ambas as disciplinas, mas as técnicas usadas continuam a ser radicalmente diferentes. Muitas firmas reconheceram a necessidade de se guiar pelo consumidor, e nāo pelo produto, investindo, por isso, grandes forças de vendas, mediante aquisições, fusões, parcerias ou aluguel de pessoal de vendas. Entretanto, até o presente, as firmas japonesas estão atrás das ocidentais no atendimento às necessidades do consumidor, que sempre mudam.

\section{PERSPECTIVAS FUTURAS: QUEM ESTÁ MELHOR APARELHADO PARA O SUCESSO?}

Vimos até agora que muitas tendências recentes sugerem que as economias de escala assumirāo importância crescente para a competitividade:

- os custos de P\&D por droga de sucesso estão subindo;

- os conhecimentos críticos de biotecnologia são muito dispendiosos;

- os prazos menores de recuperação de renda estão sendo menores, mediante aluguéis econômicos de drogas, com resultado do aparecimento dos genéricos;

- a pressão sobre margens está sendo maior, em virtude decorrente da restruturação do setor de saúde (e as implicaçôes para a competitividade dos genéricos, estrutura de distribuição/ poder de compra e conscientizaçāo do consumidor).

No final da década de 80 , muitas companhias farmacêuticas japonesas voltaramse para os EUA e para a Europa, numa tentativa de iniciar (tardiamente) uma globalizaçāo farmacêutica. Face aos sucessos ja- 
poneses nos setores de carros e eletrônicos, essa investida levou muitos a crerem que isso era um sinal do início do domínio ocidental no setor global de produtos farmacêuticos. Na verdade, ao final dos anos 80 , o Dr. Vagelos, da Merck \& Co., tinha avisado que os japoneses tinham a capacidade de fazer, no mercado de drogas, o que haviam feito no de carros.

Todavia, para as firmas japonesas que tentaram se estabelecer no exterior, foram bem poucos os resultados concretos. Como citado antes, é verdade que os japoneses recentemente fizeram extensos investimentos, nos EUA em especial, mas há vários indícios de que não só esses investimentos não integravam uma estratégia coerente de internacionalização como também de que a migração japonesa nesse processo já cessou:

- dentro da indústria farmacêutica japonesa já se estancou a demanda por serviços de investimento bancário, de consultoria e jurídicos;

- as primeiras levas de gerentes japoneses enviados ao exterior para abrir escritórios de contato estão voltando para Tóquio.

Há, contudo, muita sustentação para o argumento de que não existe nada de inerentemente "superior" na administração japonesa e que, de fato, as firmas ocidentais continuaráo a dominar ainda a indústria farmacêtica ainda por um bom tempo. Certos fatores e competências essenciais facilitaram o domínio japonês no setor de carros e eletrônicos, que sāo diferentes e náo se disseminaram para o setor de produtos farmacêuticos no Japāo:

- o papel inicial "secundário" em relaçāo ao desenvolvimento dos carros e eletrônicos japoneses significa que a P\&D governamental tem sido distorcida em favor de desenvolvimento de produtos, resultando en um déficit difícil de eliminar na pesquisa básica necessária à evolução dos produtos farmacêuticos;

- a estrutura de comercialização das drogas no Japão tem sido menos favorável (em termos de "aluguéis" econômicos) para as companhias farmacêuticas desse país do que para as daqueles ociden- tais, o que permite que estas ganhem vantagem substancial;

- os benefícios da aplicaçāo de tecnologias essenciais não são tão "óbvios" no setor de produtos farmacêuticos (reduzindo a influência de coordenaçāo do MITI e ou-

\section{O recente investimento japonês em biotecnologia básica nos EUA e Europa pode ser a única esperança da indústria farmacêtica japonesa.}

tras entidades governamentais);

- o atraso no esforço japonês de globalização do setor farmacêutico (em relação ao dos setores de carros e eletrônicos) tem possibilitado às firmas estrangeiras penetrar no mercado japonês, forçando as firmas locais a tomarem atitudes defensivas. Esse atraso tem-se dado simultaneamente com a valorização do yen, $1 \mathrm{i}-$ mitando, com isso, a capacidade de exportação das companhias farmacêuticas japonesas;

- a competência no processo de fabricação náo é de fundamental importância no setor de produtos farmacêuticos.

As companhias farmacêuticas podem ter uma vantagem se conseguirem transpor, para o gerenciamento do processo de P\&D, a sua competência no processo de fabricação, conseguindo, assim, os ganhos de eficiência exigidos para uma uma futura vantagem competitiva e para a compensação de seu menor porte. Há, todavia, indícios de que as firmas japonesas estão atrasadas nesse sentido e também na terceirização, por exemplo, de tarefas não-essenciais. $\mathrm{O}$ recente investimento japonês em biotecnologia básica nos EUA e Europa pode ser a única esperança da indústria farmacêutica japonesa, mas, para esse investimento frutificar, sāo necessários pelo menos oito a dez anos. De fato, muito tem que ser feito para as-empresas japonesas tornaremse líderes mundiais no setor farmacêutico.

\section{7}

Agradecimentos especiais vão para Paula Bignelli, S. Barbosa, Walter Cirillo, Patrick Grenham, G. Caixeta e M. Wassmer. Originalmente preparado para Gary Hamel, London Business School. 